\title{
Avaliação Microbiológica de Polpas de Cupuaçu Industrializadas e Caseiras Comercializadas no Município de Tucuruí - Pará
}

\author{
Marcos Riscik (I), Eliene Meireles da Silva (I), Luciana Mendes \\ Fernandes (I), Keiciane Souza Silva (I), Alex Odirley Feitosa da \\ Costa (I) \\ (I) IFPA-Campus Tucuruí - Instituto Federal de Educação, Ciência e Tecnológia do Pará (Rua \\ Porto Colombo, no 12, Vila Permanente, Tucuruí - PA)
}

\section{Resumo}

O cupuaçuzeiro, Theobroma grandiflorum, é uma espécie encontrada nas áreas de mata do sul e nordeste da Amazônia. O cupuaçu, tem grande importância como matéria prima em indústrias de conservas de frutas, através do congelamento. Neste contexto, o presente trabalho teve como escopo avaliar a qualidade microbiológica de polpas de cupuaçu comercializadas no município de Tucuruí-Pará. Foram analisadas dez amostras de polpas de cupuaçu, sendo cinco marcas industrializadas e cinco caseiras, durante o mês de junho/2014. Para isso pesquisou-se os seguintes parâmetros: coliformes totais e termotolerantes; bolores e leveduras; aeróbios mesófilos e estafilococos. Em (100\%) das amostras não foi detectado coliformes fecais, estando dentro dos padrões definidos pela legislação vigente $-\mathrm{RDC} \mathrm{n}^{\circ}$ 12/2001 ANVISA, que estabelece o valor < $3,0 \mathrm{NMP} / \mathrm{g}$. Apenas uma amostra (10\%) apresentou resultado positivo para coliformes totais de 4,4 x $103 \mathrm{NMP} / \mathrm{g}$, excedendo o valor mínimo estabelecido pela referida resolução. Para bolores e leveduras, as polpas industrializadas tiveram média de valores de 3,6 x $103 \mathrm{UFC} / \mathrm{g}$, com resultados variando de 1,0 x 103 a 1,0 x $105 \mathrm{UFC/g}$. Destas, duas amostras (40\%) não estão em conformidade com a IN n 01/2000 (MAPA), a qual preconiza o valor máximo de 5 x $103 \mathrm{UFC/g}$. Nas polpas caseiras, obtevese a média de 2,08 x 103 UFC/g, com variação de 1,1 x 103 a 4,3 x 103

\footnotetext{
Referência:

Marcos Riscik, Eliene Meireles da Silva, Luciana Mendes Fernandes, Keiciane Souza Silva, Alex Odirley Feitosa da Costa. Avaliação Microbiológica de Polpas de Cupuaçu Industrializadas e Caseiras Comercializadas no Município de Tucuruí - Pará. In: Anais do 12 Congresso Latinoamericano de Microbiologia e Higiene de Alimentos MICROAL 2014 [= Blucher Food Science Proceedings, num.1, vol.1]. São Paulo: Editora Blucher, 2014. DOI 10.5151/foodsci-microal-146
} 
UFC/g, estando em níveis aceitáveis conforme a referida legislação. Os resultados para aeróbios mesófilos de polpas industrializadas foram de 0,3 x 104 a 3,67 x $104 \mathrm{UFC/g}$ e para as caseiras 0,8 x 104 a 3,5 x $104 \mathrm{UFC/g}$, tendo como médias 8,36 x $104 \mathrm{UFC/g}$ e 1,1 x $104 \mathrm{UFC/g}$, respectivamente. Os valores para estafilococos presentes nas polpas industrializadas foram 0,1 x 103 a 1,79 x 104 UFC/g, e média de 4,86 x 104 UFC/g. Já a análise de estafilococos para polpas caseiras, variou de $0,1 \times 104$ a 2,1 x 104 UFC/g e média de 0,72 x 104 UFC/g. Segundo a ANVISA, não existe um valor máximo de referência para organismos mesófilos e estafilococos em polpas de fruta. A análise microbiológica para a maioria das polpas industriais e caseiras mostrou-se satisfatória, de acordo com a Agência Nacional de Vigilância Sanitária. Todavia, nas amostras de polpas que excederam o limite máximo, faz-se necessária uma melhor atenção quanto ao controle higiênico-sanitário nas unidades produtoras e de comercialização.

Palavras-Chave: polpas de cupuaçu, ánalise microbiológica, município de Tucuruí

Agência de Fomento: 